\title{
CURIOSIDAD Y MEDIACIÓN Del Lucio de Apuleyo al Anselmo/Lotario de Cervantes
}

1.

Somos de la opinión de que El Curioso Impertinente (Tomo II, Caps. 23, 24 y 25) no se puede analizar sin tener en cuenta la gran cornice constituida por la novela que lo rodea, Las aventuras del Ingenioso Hidalgo Don Quijote de la Mancha; no es menos cierto que este relato tiene una autonomía y se puede analizar también sin entrar en los paralelismos estructurales que indudablemente tiene con el todo de la obra. Estos paralelismos comienzan ya desde su colocación, no por azar simultánea en el tiempo de la narración a la lucha de don Quijote con los cueros de vino - clara referencia al episodio de Lucio y los odres de vino en el Asno de Oro de Apuleyo, la más elegante obra latina sobre la curiositas.

Mientras en otra estancia don Quijote se bate con los cueros (como Lucio, el curioso, con los ladrones, que son otros tantos odres de vino, en El Asno de Oro de Apuleyo), el cura pregunta al ventero qué contiene cierta maleta olvidada por un viajero; entonces, el cura ve unos folios escritos con bella grafía, en la citada maleta, y le domina el deseo de ver su título: Que es "Novela del Curioso Impertinente". Inmediatamente tiene ganas de leerlo todo. Cervantes alude al hecho de que, en el leer un relato sobre la curiosidad, la curiosidad está ya presente en el sentido de que ya hay un lector:

"Pues desa manera — dijo el cura—, quiero leerla, por curiosidad siquiera: quiza tendrá alguna /curiosidad/ de gusto." (1986:200)

La técnica que consiente a Cervantes que los sucesos inmorales en el Curioso sean osée y explícitos es precisamente el relato a cornice, el recurso al relato hallado por casualidad, que exonera a Cervantes de responsabilidad sea respecto a la veracidad sea respecto a la ejemplaridad de un relato que viene, después de todo, interpolado. Además el cura hará un generoso comentario que quita hierro al asunto. Como buen cura, dirá que esta historia es inverosímil en un matrimonio, pero plausible en una pareja aún no casada. Lee la novela en voz alta para las personas de la venta, y todos ríen de la simplicidad del curioso Anselmo, sin caer en la cuenta de que ellos mismos están cayendo en la tentación de leer un escrito privado, o sea de complacerse en una ilícita curiosidad. No obstante, la curiosidad no reviste para el cura los tintes diabólicos con que la juzgara Plutarco, sino la erasmiana locura de un reverso de don Quijote.

La curiosidad en Cervantes viene de todas maneras castigada con la pérdida de la felicidad conyugal y con la muerte final del curioso; quizás en esta condena de la preocupación por aquello que no nos concierne, esto es, lo impertinente, se pueda hallar una similitud entre las tomas de posición de Cervantes y las de Epicuro frente al curioso. De 
hecho, si Epicuro afirma que no se debe hurgar en los secretos de la naturaleza, Cervantes a su vez aserta que no se deben mezclar los calmos humores de la propia esposa sólo por una vana e impertinente curiosidad.

Constatamos que un parecer similar se vuelve hallar en el Arcipreste de Talavera, coevo de Cervantes y autor del así llamado Corbacho español, obra maestra de la misoginia curial en la cual se intenta demostrar la volubilidad de la mujer. Sea Cervantes en el Curioso Impertinente, sea el Arcipreste recomiendan el mayor celo posible comparando la mujer a una joya, que puesta a prueba puede quebrarse.

Cervantes propone, como antagonista del curioso, al discreto; pero veremos que el discreto que nos presenta tiene tanta discreción como el peor de los curiosos. Finalmente, apoyándonos en las directrices propuestas por René Girard, contemplaremos desde la perspectiva de la mediación interna, un posible análisis del problema. Quizás no se trata de un curioso, sino de dos curiosos que acabarán por iniciar en el secreto a la casta Camila no menos que al curioso lector.

\section{La mirada impertinente del curioso}

El hombre moderno con sus contradicciones está ya en Cervantes como lo está en Hamlet; no se trata tanto de temer el juicio de Dios como de afrontar la mirada del Otro. Anselmo decide desposar a Camila, jovencita bella y de buenas partes, pero necesita pedir opinión a Lotario. Lotario está de acuerdo y pide por Anselmo la mano de Camila, recomendándolo y haciéndose su garante. Una vez casados, Lotario mismo decide no frecuentar la casa de la pareja para evitar, dice, los murmullos de las gentes; ahora bien, es él quien enciende los celos de Anselmo con tal supuesta discreción ya que no puede decir esto sin dar a entender a Anselmo que sería peligroso tener cerca de su mujer a un hombre como Lotario, porque, a buen seguro, era una tentación, como lo confirma su certeza de que habria habladurías. Anselmo, no menos cortésmente, responde que de haberlo sabido no se habría casado; y así Lotario obtiene el poder frecuentar la casa y a la vez pasar por discreto a los ojos del lector. Pero en vista de que la táctica le va bien, se permite ir con calma, y finge hacer las visitas a pesar suyo. Lógicamente, Anselmo, inconscientemente o no, ofendido de una tal prepotencia, le propone una bocacciana trampa: cortejar a Camila. De acuerdo con la más estricta regla cristiana hay una resistencia inicial de Lotario, pero ante la insistencia "inexplicable" y "connatural" de Anselmo, finge el cortejamiento, o, como hemos visto, finge fingirlo... ya que de acuerdo con el fatalismo sexista bocacciesco, un deseo irresistible, nacido al parecer de la nada, triunfa sobre la férrea voluntad el discreto, después de todo humana, y éste se enamora de la noche a la mañana de Camila y/o de la traición que cada vez va prendiendo más en él, que poco antes se preocupaba de leves murmullos de las gentes.

El gusto renacentista por la paradoja parece brillar en Anselmo, celoso en la calma y calmo cuando debería sospechar. Cuando Anselmo se quita la vida nos parece un castigo por querer ver a través de los ojos del Otro, por penetrar en las vísceras de la naturaleza y arriesgar la felicidad a cambio de la verdad. Cervantes mismo diagnostica así su mal. No de otro modo lo habrían diagnosticado tanto Epicuro como Plutarco. La curiosidad es por tanto una enfermedad que es preciso castigar o curar. En Agustín es claramente la fides 
cristiana la cura a la tentación de la curiositas o concupiscentia oculorum. Se trata de creer sin ver, interiormente, en vez de querer ver lo nunca visto incluso a riesgo de la perdición. La salvación requiere la convicción no sólo como sugestión, sino también como causa necesaria, origen de la misma salud. El honor no es separable de la fama y la honestidad no es más que la convicción que de ésta se tiene. Traslocando el argumento desde el hombre agustiniano, medieval, hasta el erasmista, para Cervantes la salvación consiste en el creer en el Otro sin pedirle milagros, idea frecuente en los Evangelios, como cuando Jesús dice al Diablo: "No tentarás al Señor, tu Dios", y cuando dice a Tomás el discípulo: "Dichosos los que sin ver creyeron". El curioso no se preocupa de ser dichoso, beatus, como Jesús, sino de ver, como el Diablo. Por eso Anselmo no tiene tanto miedo de perder al otro, a su Dios, como de saber aquello que el Otro, su Dios, sabe. Como Eva en el Libro del Génesis, es feliz, pero quiere saber lo que Dios le prohibe, y precisamente, elige entre todos los árboles del Paraíso aquel que Dios le niega. El criterio de selección viene confirmado por una serpiente, un consejero venenoso, traidor, serpeante, espiraliforme, o sea, el original pecado de la curiositas. Del mismo modo, Anselmo, casado bien y recientemente, está en una situación paradisiaca; y pide aquello que explícitamente su Dios le niega. Cuanto más rehusa Lotario, tanto más crece el deseo de Anselmo; es el obstáculo lo que decide la meta, ya que el objetivo pertinente al curioso es lo impertinente, es decir, el único árbol con valor distintivo, semántica e intelectualmente único signo pertinente en medio de la verde indiferenciación del Paraíso.

René Girard, en el estudio que hace del trickster escandinavo, analiza los excesos de una recreación culta del mito, que halla en todas las culturas, desde Grecia hasta los mitos solares aztecas.

Según Girard, estas reelaboraciones se producen cuando en un momento histórico la crudeza del mito llega a resultar intolerable para los que creen en su verdad, como por otra parte le ocurre al Platón de La República, porque la maldad de los Dioses debería ser negada. En el caso del trickster escandinavo, esta reelaboración culta ha buscado en Loki un malvado único, con el fin de disculpar a todos los otros Dioses. Höhr forma parte del círculo de los Dioses - según Girard serían los ancestros- que, creyéndole invulnerable, golpean hasta matar a Baldr. Pero Höhr en el mito es la mano ejecutora propiamente dicha, y la versión culta que nos ha llegado lo disculpará en un grado proporcionalmente mayor. Disculpa que empero resulta sospechosa a medida que Girard va observando la religiosa escrupulosidad de las excusas, demasiado proporcionadas conforme a la vecindad al homicidio, para ser casuales; Höhr es el único Dios que no sólo cree que Baldr sea invulnerable - como si para justificarle por alguna razón no bastara esta excusa-, sino que es además ciego y el arma que usa es insignificante, una pequeña rama de la más tierna planta, (tan tierna que es el único ser que no había debido jurar que no heriría a Baldr). Curiosamente, Höhr resulta el único dios triplemente inocente de un homicidio del cual sólo él es técnicamente culpable. Esto hace pensar en las sospechosas marcas de inermidad acumuladas sobre David, sea su pequeñez, sea la grandeza de Goliath, sea su juventud, sea su tierna honda, arma insignificante. Vemos tras la femineidad de David la ceguera de Höhr, tras la honda, la rama de Höhr. Todas las culturas primitivas se excusan de modo similar de crímenes similares entre sí. 
El deseo de simular en exceso, la excusatio non petita, termina siempre por revelar la simulación. Ese deseo resulta tan evidente que anula a su alrededor todo aquello que podría distraernos y nos dirige directamente hasta la cosa disimulada. Esta es la lección de Girard; sin necesidad de forzar un texto, antes bien, a partir de éste, consideramos que es posible una lectura similar del Curioso Impertinente que explicase todas las premisas -que aparecen con religiosa escrupulosidad - a cada burla y engaño obrado por Lotario, a partir de un único principio: la excusación progresiva de Lotario contemporáneamente a la acumulativa culpabilización de Anselmo, por parte del autor culto en cuestión. Y como Lotario es la mano ejecutora, el relato lo disculpa, como el mito exculpa a Höhr, en un grado proporcionalmente mayor; Lotario no solamente está impulsado por Anselmo, que es un celoso, sino que además Lotario lo hace todo filantrópicamente, explicando ad nauseam que aquel es el camino equivocado para luego de punta en blanco tomarla él mismo. El grado más cruel, la escena del cuchillo, viene precedido de una serie de combinaciones de fatalidades, mientras que traiciones en una escala menor no son debidas al destino, sino que bastan excusas menos fuertes, como la insistencia del celoso. Además, el arma de Lotario, su silencio, es insignificante como la rama de Höhr o la honda de David. Evita hablar con Camila, y esto, unido a la insistencia de Anselmo, le vuelve doblemente inocente de un adulterio del que, se diría por mera fatalidad, es técnicamente culpable. Cervantes no deja de decirnos, quizás maliciosamente, que en el mundo entero no ha existido nunca un amigo como Lotario. Y Lotario, en su papel de Amo, se revela como un curioso de guante blanco, más sofisticado, pero simplemente un curioso vuelto del revés.

3.

Es precisamente la unión demasiado fuerte la que lleva al desastre a "los amigos". El mimetismo frente al modelo se quiere escrupuloso; desafortunadamente, el uno necesita de la envidia del otro, como prueba de su triunfo. Porque el éxito por sí mismo no era lo realmente deseado. ¡Nada de una curiosidad ligera! Se trata de una necesidad. La remisión de Lotario a cortejar a Camila provoca una amarga queja en Anselmo, que Cervantes considera, muy erasmianamente, "locura", pero si buscamos una explicación a esa locura sólo se explica en términos de un despecho de Lotario; en términos, concretamente, de rivalidad en la elección dẹl objeto, donde la rivalidad por la posesión pasa a segundo plano. Cuando leemos que Anselmo está enfurecido porque Lotario no le hace un favor inadmisible, nos parece tal locura, porque lo sería. Pero el texto no explica lo que ocurre. No está Anselmo ofendido porque su amigo rechace obrar deshonestamente. Está ofendido porque Lotario no se muestre lo más mínimamente tentado por Camila, justo ahora que creía haberle superado poseyendo un objeto deseado por Lotario.

Nuestra interpretación la confirma el texto con la reiterada ad nauseam lista de expresiones de unión: los amigos eran llamados por antonomasia; "mozos de una misma edad y de unas mismas costumbres"; "andaban tan a una sus voluntades que no había reloj concertado que así lo anduviese". ¿Qué es todo esto, sino mimetismo?

La unión espiritual exige por lógica que ambos deseen las mismas cosas, tengan los mismos gustos, y por tanto la rivalidad es innegable. La curiosidad impertinente no tiene nada que ver con la ingenua distracción agustiniana que hace salir de la eternidad contem- 
plativa y entrar en el mundanal tiempo; no es tampoco la curiositas contagiosa de ver espectáculos sanguinarios en la arena circense, como sucede a alipio, el discípulo de Agustín; ni tampoco es un curioso de la intimidad ajena que ama hablar mal y pensar mal como aquel de Plutarco. Se parece superficialmente al periergos de Teofrasto, aquel que siempre va más allá de sus posibilidades. Pero, a diferencia de todos ellos, el impertinente es consciente de su exceso cuando dice que sabe ir escapando del bien y en pos del mal. La curiosidad no ingenua de Anselmo mete las narices en su propia vida, o sea en un tema pertinente. Opera sobre aquello que le concierne, pero con un exceso de celo, de cura. Como su propio juez-arbiter, su propio demonio, como el Dios providente y omnividente criticado por Cicerón en los paleocristianos, o como las efigies de Epicuro llevadas por los epicureos para sentirse vigilados por su maestro, Anselmo ansía ver dentro de la naturaleza de Camila, hurgar en el mecanismo de la felicidad, disfrutar en definitiva el usufructo de su dote perversamente — perversa administratio conditionis agustinianaLa traición es dura, pero la verdad es más importante, y con el fin de ver, su curiosidad le lleva a desear su propio mal, ya que, para poder estar abí escondido en la oscuridad cuando le estén traicionando, y no perderse nada, ¿qué mejor que provocar la traición él mismo?

El nombre de curiosidad impertinente es realmente adecuado, porque los otros tipos de curioso observan y experimentan sobre lo que no les atañe, pero en nuestro caso no se puede decir que la materia sea impertinente; es la misma escrupulosidad del celo, la que es impertinente, del mismo modo que quien se mira durante horas en el espejo no se ve a sí mismo, sino cómo es visto, o sea, espía la mirada de los otros. Anselmo es un supersticioso y celoso custodio que llega a favorecer la ocasión de lo mismo que condena. Por lo demás, Lotario está lejos de representar el discreto como se nos quiere hacer creer; no es poca la inquietud que le ha llevado a casar en práctica a dos personas que no sólo quizás no lo habrían hecho sin su ayuda, sino que quizás lo habrían hecho sin su ayuda - y él les roba esta autonomía, aun cuando sea con la aquiescencia general. He aquí el triángulo girardiano del deseo mimético; Lotario ha decidido los deseos de Anselmo en el mismo sentido en que Amadís de Gaula los de Don Quijote de La Mancha. Se ha establecido una mediación.

En realidad no es raro que Anselmo acuda precisamente a Lotario; Camila deviene tan sólo un objeto de la rivalidad sin valor intrínseco. De hecho, Anselmo, que tiene más confianza en el amigo que en sí mismo, tiene ciertamente más confianza en el amigo que en la propia esposa. Cervantes no intenta trucar de ciencia la curiositas, como se hace a menudo para desinfectarla de su verdadera semántica, y el carácter maligno de la empresa queda claro desde un comienzo. Si Anselmo no cree en lo que tiene, es porque no to ha elegido él; y esto, que en Cervantes es curiosidad inexplicable y egregia locura novelesca, no es sino transparente y lógica rivalidad en la mediación interna. A diferencia de la mediación externa de un mediador ideal como Amadís, de un cavaliere inesistente, la rivalidad en la mediación interna está apenas un escalón por debajo del rito sacrificial victimario más primitivo. Al final del relato todos mueren. A causa, creemos, no de la malvada curiosidad viciosa, sino de la pocas veces criticada compenetración, sociedad, llevada más allá del extremo de lo pertinente. 
Textualmente, la curiosidad es el chivo expiatorio, conceptual, el elemento psíquico condenado para purgar todas las contradicciones de la discreta amistad que nunca se mancha las manos. Para que cualquier sociedad evite afrontar sus crisis basta hacer reposar toda la culpa - y el castigo- sobre uno solo de los elementos desencadenantes, que es con frecuencia el más inocente, ya que eso lo señala como claramente victimario. Esto es el rito sacrifical.

La curiosidad no es, indudablemente, una virtud, ni una vía de conocimiento ordenada, odia las jerarquías, busca y encuentra el error; y es ello lo que hace turbarse tanto al así llamado discreto, quien, de la verdad, no quiere saber demasiado, lo cual no deja de ser paradójico en un modelo de virtuoso.

Fortuna para nosotros, lectores, es que haya curiosos escritores que puedan dirigir sus fantasmas en el sentido de la autobiografía de lo posible peligroso. Cervantes, en su condena del curioso, lo elige como tema, y no olvida cuánto debe él mismo, y todo el que valora la imaginación, a la novelesca curiosidad.

Bibliografia

Cervantes, Miguel de, El Ingenioso Hidalgo don Quijote de la Mancha.

Madrid, Espasa-Calpe, 1986.

Girard, René, El chivo expiatorio. Barcelona, Anagrama, 1986.

Girard, René, Mentira romántica y verdad novelesca. Barcelona, Anagrama, 1985.

Tasinato, Maria Angela, Sulla Curiosita. Parma, Pratiche, 1994.

\section{Povzetek}

\section{RADOVEDNOST IN POSREDOVANJE}

Avtor članka analizira pripoved o Predrznem radovednežu v Cervantesovem romanu Bistroumni plemič don Kihot iz Manche. Anselmo se pred poroko posvetuje s prijateljem Lotariem o svoji izbranki. Po poroki se Lotario izogiba hiše mladoporočencev in s tem vzbudi Anselmovo radovednost. Da bi preskusil ženino krepost, ta naprosi prijatelja, naj jo zapelje. Boccacciovska konstelacija, pojmovana kot mimetična želja po Renéju Girardu, je sledeča: zaradi mimetičnosti želje je uspeh (posedovanje objekta) obeh rivalov šele drugotnega pomena. Pomembnejša je skupna izbira objekta. Tega po Girardu vedno določa Drugi, zato hoče radovednež (Anselmo) videti ravno to, kar mu je ta (Drugi, Bog) prepovedal. Gre za notranjo posredovanje (mediacijo). Radovednost pa je pravzaprav žrtveno jagnje, saj je radovednež $v$ zameno za resnico kaznovan $\mathrm{z}$ izgubo zakonske sreče in s smrtjo. 